The Periodic-Table - A Universal Icon: Its Birth 150 Years Ago, and Its Popularization Through Literature Art and Music

Sason Shaik ${ }^{*[a]}$, Eduard Cremades ${ }^{*[b]}$ and Santiago Alvarez ${ }^{*[c]}$

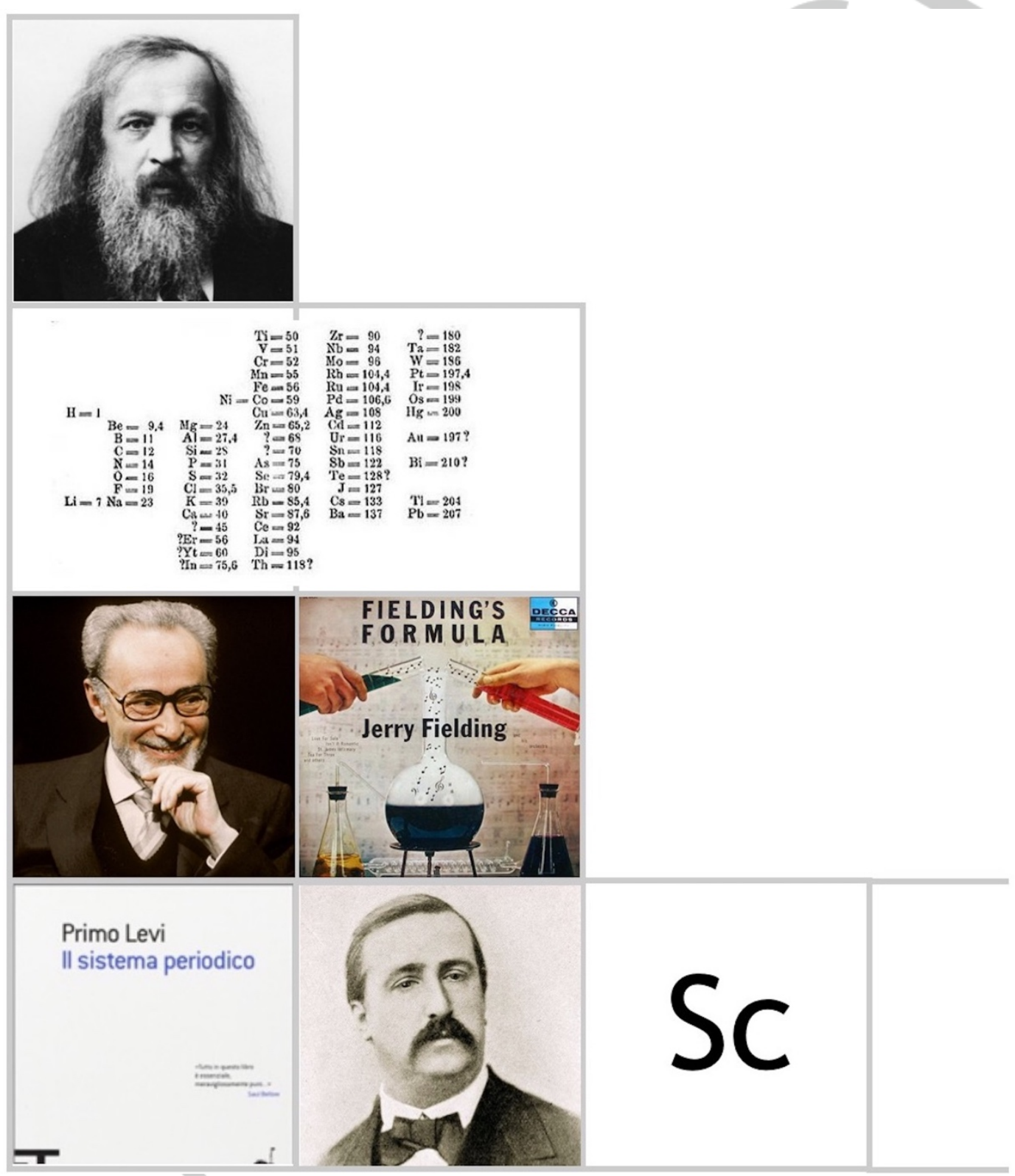




\title{
The Periodic-Table - A Universal Icon: Its Birth 150 Years Ago, and Its Popularization Through Literature Art and Music
}

\author{
Sason Shaik ${ }^{*[a]}$, Eduard Cremades ${ }^{*[b]}$ and Santiago Alvarez ${ }^{*[c]}$
}

The essay is dedicated in memoriam of Prof. Joel Bernstein who passed away in the midst of a thriving career

\begin{abstract}
This essay projects the spark of genius of Mendeleev, whose efforts led to the effective formulation of the Periodic Table, which has placed the entire world of chemical matter on a palm. The Periodic Table gave rise to a central paradigm, which did for chemistry what Newton had done for physics and Darwin for biology. Subsequently the essay recounts the popularization of the Periodic Table through literature by Primo Levi, Oliver Sacks and others, and through music and art by composers and artists, such as Jerry Feldman, the King Crimson band, Tom Lehrer, and George Brecht, Blair Bradshaw, Eugènia Balcells ...
\end{abstract}

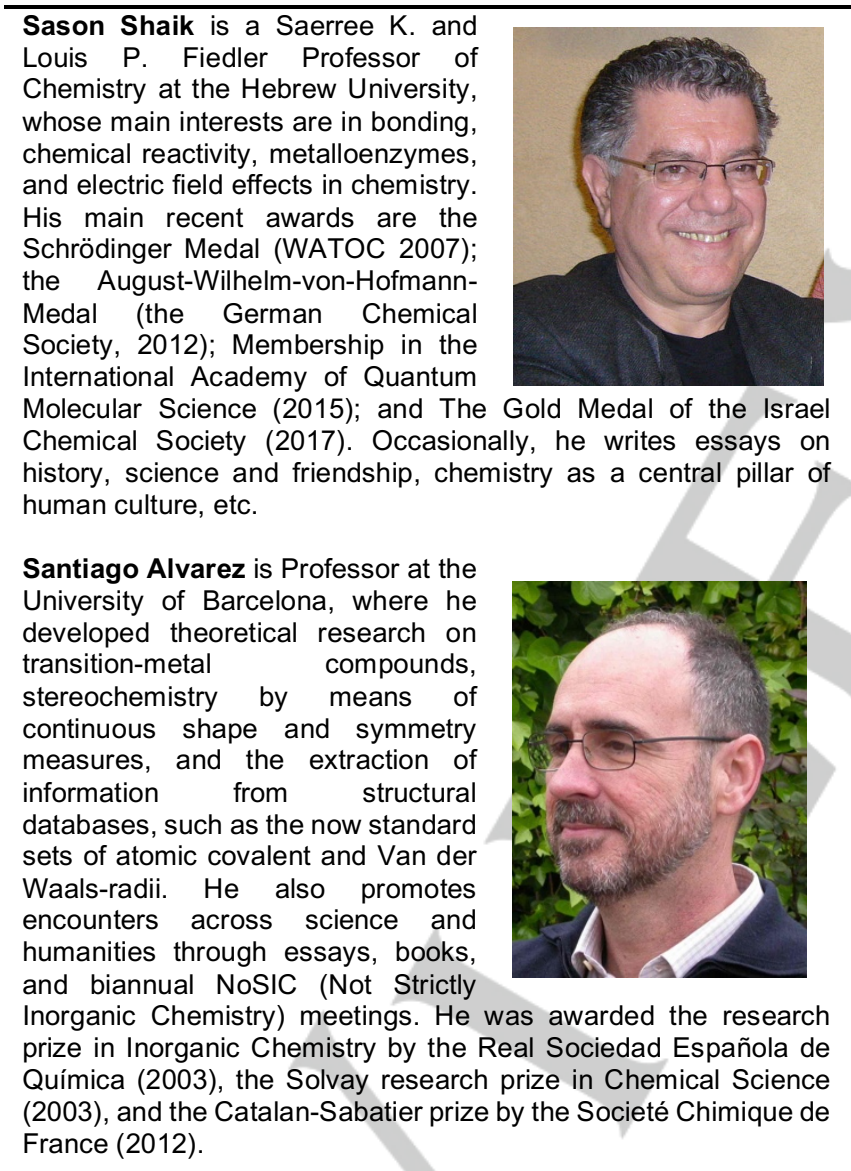
France (2012)

\footnotetext{
[a] Prof. S. Shaik, The Hebrew University of Jerusalem, The Institute of Chemistry, Jerusalem 9190400, Israel , sason.shai@gmail.com

[b] Prof. E. Cremades, Escola Isabel de Villena, Joan Miró 41-43, 08950 Esplugues de Llobregat, Spain

[c] Prof. S. Alvarez, Universitat de Barcelona, Departament de Química Inorgànica i Orgànica and Institut de Química Teòrica Computacional, Martí i Franquès, 1-11, 08028 Barcelona, Spaiin
}

\begin{abstract}
Eduard Cremades is Head of Studies in Escola Isabel de Villena in Esplugues de Llobregat. He got his Ph. D. in the Electronic Structure Group of Professor Santiago Alvarez in Universitat de Barcelona in 2012, for his work related to single molecule magnets. Since then he has been teaching chemistry in high school, participates in different science popularization projects and is constantly searching for relationships between chemistry and popular culture.
\end{abstract}

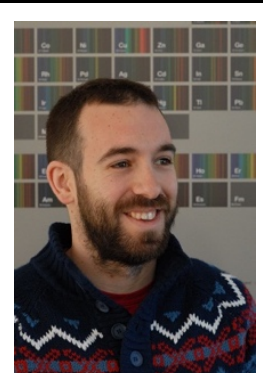

\section{Introduction}

The heated debates of chemists during the 19th century formed the background for Mendeleev's periodic Table. ${ }^{[1-3]}$ Figure 1 shows the explosion of information on "chemical elements" in the post-Lavoisier's era. ${ }^{[4]}$ The definition of a "simple body" by Lavoisier ${ }^{[5 a]}$ provided the chemists with an effective manner of discovering new elementary materials. These were materials that could not be decomposed into simpler ones within the technical means of a given time. This definition has led to the discovery of many elements, ${ }^{[6]}$ and suddenly there seemed to be too many ... The chemists feel being cast out of Paradise: they start to yearn for the simple world of 4-elements (air, earth, fire and water) and the quintessence (protyle). ${ }^{[2 b, 3 c, 5 b]}$ However, as soon as the recognition sets in that this paradise is gone forever, the next best is to find "orders and rules" in the information.

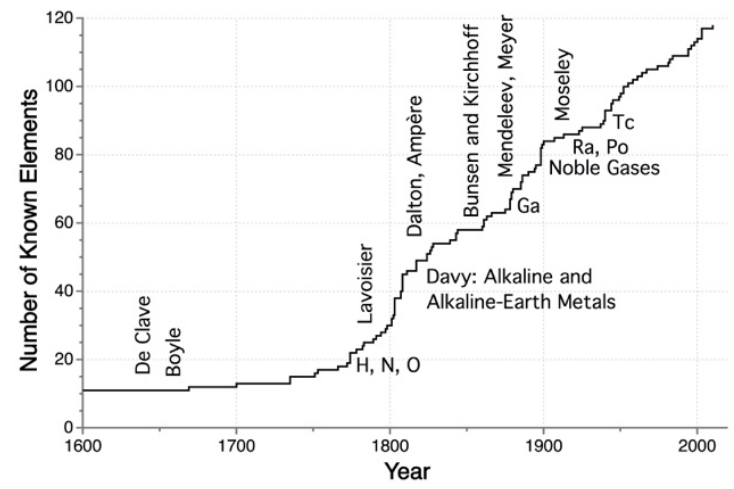

Figure 1. A plot of the number of elements discovered per year. Adapted with permission from Ref. 4.

A major step towards order was the atomic hypothesis by Dalton (1803). ${ }^{[5 c]}$ John Dalton (Figure 2a) argued that the mass of matter is quantized as atomic particles. He created calculus for 
estimating atomic weights (AW), and he defined molecularchemical-identity in terms of atomic combinations. Some chemists like Wurtz, Laurent, Gerhardt (Figure 2b), etc., accepted the atomic postulate. Others like the physicist Ernst Mach, and the chemists Berthelot and Dumas (Figure 2c) rejected it. ${ }^{[7]}$ Dalton's calculus was imperfect and generated different AW values for the same element. This brought about too much confusion. So much so that Dumas declared (in 1837) "If I were master I would efface the word atom from science".

Then came the Karlsruhe conference in 1860. This was the $1^{\text {st }}$ symposium of chemistry. During the symposium, Cannizzaro (Figure 3a) used the Avogadro hypothesis [that equal volumes of gases involve the same number of molecules, and that "simple bodies" like hydrogen and oxygen involve union of the same atoms] ${ }^{[2 a, 5 c, 7]}$ and generated a set of consistent $A W$ values based on a scale with $\mathrm{H}=1 \mathrm{au}$. He defined the "mole" and the volume of mole, as well as valence; the latter as the ratio of the AW to the combining weight (e.g., for oxygen valence $=16 / 8=2$ ). The speech of Cannizzaro was fiery and spellbinding, and had a major impact on the thought of chemists, who were more accustomed to equivalent weights (the combining weights). ${ }^{[3 b]}$

The Karlsruhe conference marked the right time and required the right person to produce the necessary order in the elements. In hindsight, the right person for the task was the young Mendeleev, who was present in the conference together with his friend Borodin (later to become a famous composer), and Lothar Meyer, among others.

(a)

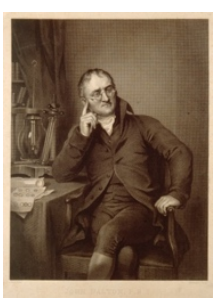

(c)

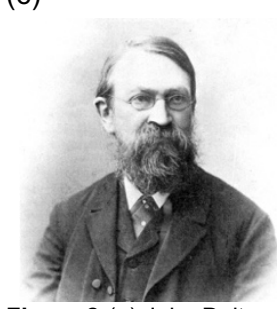

(b)
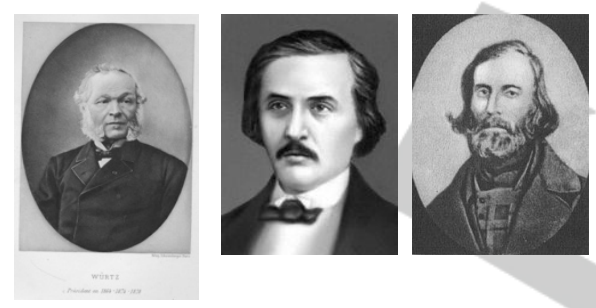

Figure 2:(a) John Dalton. (b) From left to right: Charles-Adolphe Wurtz, Charles Gerhardt, and August Laurent. (c) From left to right: Ernst Mach, Marcellin Berthelot and Jean Baptise André Dumas. Taken from commons.wikimedia.org

Mendeleev was the right person for many reasons, first and foremost his personality, which will be discussed later, but also the fact that he was an admirer of Newton ${ }^{[2 a]}$ and his concept of "mass", which Mendeleev just witnessed it being fleshed out in the conference. But also because he had visited France and was influenced by Dumas and Gerhardt's theory of "types". ${ }^{11, e ;}$ 2a] On his impression of Cannizzaro's new order, Mendeleev writes: "I vividly remember the impression produced by his speeches, ... which seemed to advocate truth itself ... Only such real atomic weights ... could afford a basis for generalization". ${ }^{[3 b]}$ Mendeleev will take on the Karlsruhe lesson, will disregard the term "simple body", and replace it by a constant of the "element", the AW. ${ }^{[8]}$ He will usher thereby a major new paradigm for chemistry; one that is equivalent to the Newton's work for physics and Darwin's for biology. ${ }^{[3 a, 8,9]}$

(a)

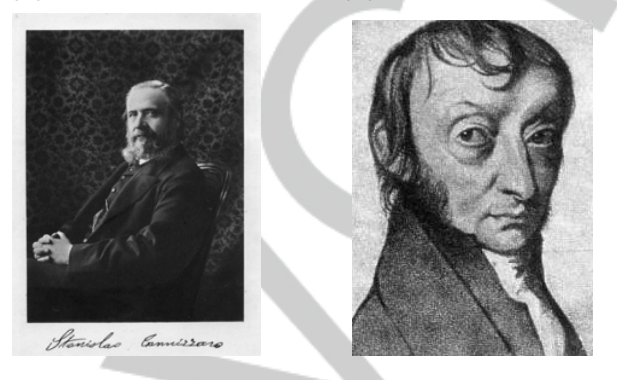

Figure 3. (a) Stanislao Cannizzaro. (b) Amadeo Avogadro. [Taken from commons.wikimedia.org]

\section{Who Was Dmitry Mendeleev?}

Mendeleev was born in 1834 in Tobolsk in Siberia to Maria Dmitrienvna Kornilieva Mendeleeva and Ivan Pavolovich Mendeleev, who was a school principle. ${ }^{[10,11]}$ Dmitry was the youngest of the 11-17 children (depending on the source) the couple had. Already in 1847 the father died of Tuberculosis. To assist the family, the mother re-established her own father's glass factory and managed it. Shortly thereafter, when the factory burns down, she takes Dmitry and his older sister Liza and she hitchhikes very long distances ${ }^{[2 a, 3 b]}$ to Moscow and then to St. Petersburg to find for Dmitry proper education, which she finally does in 1850 in the Pedagogical Institute in St. Petersburg. In the same year she and her daughter Liza died of Tuberculosis.

It is clear that his mother (Figure 4) was the main figure and driving force in his life, as he writes in his memoires:[2a] "Conducting a factory, she educated me by her own words... corrected me with love... She gave me my mission in science: She left Siberia with me, spending her last resources and strength..." Mendeleev further adds that before she died she advised him to refrain from illusions, to insist on work, not on words, and to patiently seek the divine and the scientific truth. ${ }^{[3 b]}$ He followed her legacy...

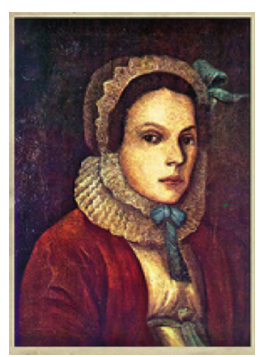

Figure 4: Maria Dmitrievna Kornilleva Mendeleeva. [Taken from commons.wikimedia.org] 


\subsection{Mendeleev's Family Life}

Mendeleev got married twice and had six children. It is doubtful he properly divorced his first wife, and he married his second wife after a romance of more than four years. ${ }^{[2,12]}$ At age 43, he became fascinated by a young 19 years old art student, Ana Ivanovna Popova, after hearing her playing at his home the piano part of Beethoven's Emperor Concerto. ${ }^{[13]} \mathrm{He}$ fell in love desperately and courted Ana. He even threatened to commit suicide if she did not marry him. ${ }^{[10]}$ She finally agreed in $1881-2$ (Figure 5).
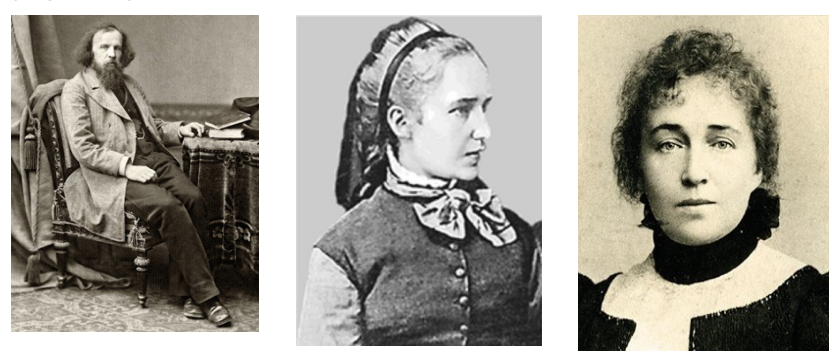

Figure 5: Mendeleev (around 1880), and Mendeleev's second wife, Ana Ivanovna Popova younger and older (ages not known). [to the best of our judgement and extensive search, the photo of the younger woman, taken from a Russian site, was judged to be of Ana Ivanovna Popova] [Taken from commons.wikimedia.org]

His improper divorce, and having remarried without the cooling period of seven years as required by the Orthodox Church, caused a public uproar, which is said to have caused Mendeleev's membership rejection in the Russian Academy of Sciences. It is further told ${ }^{[2 a, 3,14]}$ that the Nobles and Courters envied Mendeleev, and requested the Czar (Tsar) to allow them to marry two wives like Mendeleev. The Tsar answered: "We admit that Mendeleev has two wives, but We have only one Mendeleev".

The intensity by which Mendeleev courted his second wife is the same driving force behind his relentless perusal of the Periodic Law.

\subsection{Mendeleev's Carrier on the Fly}

In 1861, after a postdoc with Bunsen in Heidelberg, with whom Mendeleev did not get along too well, ${ }^{\left[{ }^{[3}\right.}$ he returns to the University of St. Petersburg. In the same year, he writes his first book "Organic Chemistry", which became influential in Europe. In 18867 he gets promoted to a chaired professor, and writes his second book "Principles of Chemistry" (Osnovy Ximii), published in 1868. On the first volume of Osnovy Ximii, Mendeleev writes, "My favourite child ... it contained my likeness, my experiences... and my most sincere scientific ideas". ${ }^{[3 b]}$

Early on, he cultivates an eccentric mannerism, which outwardly is expressed in growing hair without cutting it more than once a year (Figure 6). As Strathern ${ }^{[3 b]}$ describes him: "His intense, deep-set, blue eyes, his flowing beard and hair made him almost messianic figure ... a prophet of science and rationalism". As such, he is also a hypnotic ${ }^{[2]}$ and popular teacher, and this leads him to support students unrest in 1890. Consequently he is dismissed of his position in the University.

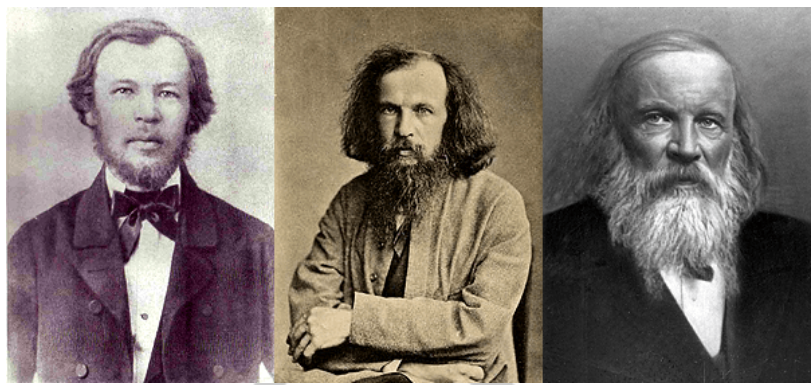

Figure 6: Mendeleev during his career as professor of chemistry, from left to right: the young Mendeleev 1860, middle aged, and older. [commons.wikimedia.org]

In 1893, he is appointed as Director of the "Bureau of Weights and Measures", and introduces the metric system in Russia. He helps establishing the Russian Chemical Society, and the first oil refinery in Russia (Baku). ${ }^{[2]}$

Mendeleev's contributions are highly appreciated in Europe, ${ }^{[15]}$ and among other awards, he receives the Davy(1892) and the Copley Medals (1905) of the Royal Society. In 1906 Mendeleev was a candidate for the Nobel Prize, but he lost by one vote to Moissan. ${ }^{[7]}$ According to rumours, Arrhenius objected to this candidacy due to a grudge against Mendeleev who did not support his dissociation theory.

Mendeleev passed away in 1907 (January $1^{\text {st }}$ ), due to severe influenza. His wife Anna read on his grave Jules Verne's "Journey to the North Pole", a gesture which may reflect her admiration for her pioneer spouse. His students carried a periodic table in his funeral, and his tombstone in St. Petersburg carries only his name; a sign of great fame - someone who needs no introduction. The wall of the Bureau of Weights and Measures carries now his last version of the Periodic Table, which was engraved in 1934. He became a Russian hero, and appeared on stamps (Figure 7), and in many public monuments. ${ }^{[12]}$ (a)

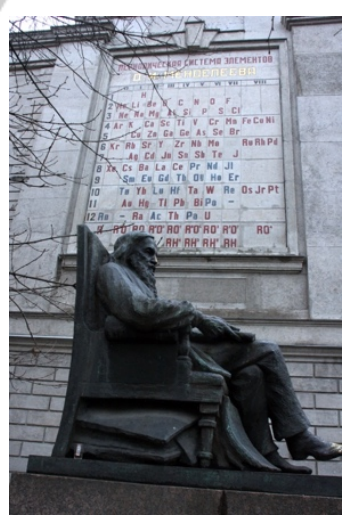

(b)

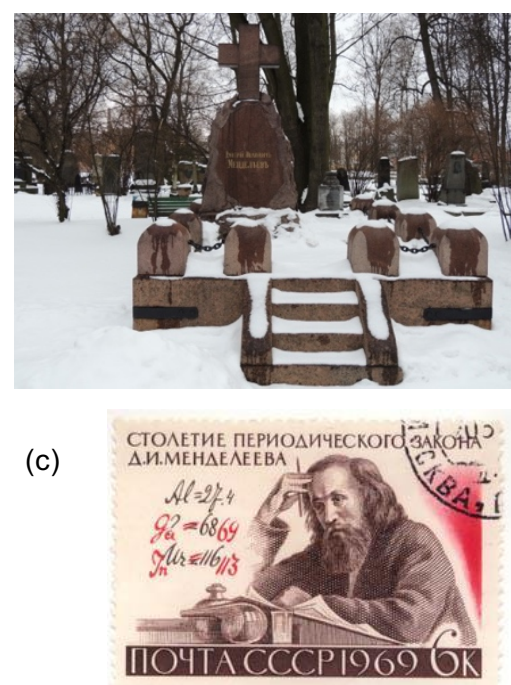

Figure 7: (a) Mendeleev's Periodic Table Gıyı aveu viı uı vvall vi uı vuı cau uı Weights and Measures, along with his statue in front. (b) His tombstone - with engraving of his name-Mendeleev. (c) A stamp commemorating Mendeleev and the 1869 Periodic Table. [commons.wikimedia.org] 


\section{Mendeleev's Periodic Table}

Mendeleev's motivation in his scientific quest sprung from his being a teacher. Already in 1861 he realizes that students of chemistry had difficulties just memorizing facts, and he notes to himself that "the edifice of science requires a plan....". ${ }^{[3]}$ In the very same year, he worked like a demon and completed for his students in 61 days a 500 pages textbook "Organic Chemistry". [2 7]

\subsection{Mendeleev's Game of Solitaire}

In 1868, Mendeleev wrote the two volumes on The Principles of Chemistry (Osnovy Ximii), and started to organize the then known 63 elements. The properties of the alkali metals and alkaline-earth metals, discovered by Davy, provided Mendeleev initial clues to such an eventual order. ${ }^{[2 a]}$ Being a Newton's admirer he naturally used the atomic weight (AW) as an organising principle..$^{[2]}$ In this manner he attached to the "element" a "fundamental constant" which is unrelated to the state of division of the "simple body", and which is expressed in all compounds of the element. ${ }^{[1 \mathrm{~d}, \mathrm{e} ; 8]}$ But Mendeleev immediately realized that he needed more properties as additional organizing criteria, e.g., valence. According to some sources, ${ }^{[1,2,2,3]}$ he wrote the names and properties of the elements on cards, which he used to carry in his pockets. And like a game of Solitaire, he tried to organize these cards in ways which would give rise to 'order'.

During three intense days- before a trip he had to make to Tver, to speak to the delegation of cheese makers- he racked his brain in an effort to find order in his cards. But each time he seemed to have understood the rules that governed the order, these eluded him. Known for his volatile temper, Mendeleev was getting tense, extremely upset, and exhausted, his head fell on his desk and he fell asleep and had a dream. ${ }^{[3 a, b]}$ In a passage, which is reminiscent of the Kekuléan dream (1862), on the structure of benzene, Mendeleev writes in his memoirs: "I saw in my dream a table, where all the elements fell into place. Awakening, I immediately wrote everything down on a piece of paper". ${ }^{[3 a, b]}$ This beautiful story (like the story of Kekulé's dream) is thought to be a myth, but who can really tell someone if he/she dreamt something or not? And, why does it matter if this is only a story told in hindsight? And if he never played with cards to achieve the order?

\section{The 1869 Periodic Table and Its Predictivism}

Mendeleev named his device the "Periodic Law of the Elements". Figure 8 a shows one of the many drafts ${ }^{[1 \mathrm{e}]}$ he created that carries the date 18.2.1869. In February 1869 he wrote a leaflet titled Essay on a System of the Elements, based on their atomic weights and chemical affinities, of which 150 copies were printed in Russian and 50 in French and sent out to colleagues.

A paper with the table was published in 1869 in the first issue of the Journal of the Russian Chemical Society, edited by Nikolai Menschutkin (Figure 8b), who also read the paper in March in front of the society in Mendeleev's absence. ${ }^{[16]}$ Figure $8 \mathrm{c}$ shows the published and reprinted Tables, and one can see that there are here and there question marks, which as we shall see

in a moment make Mendeleev's Table a very powerful device.

\subsection{Mendeleev's Powerful Device - Context in Empty Spaces}

After having generated the Table, Mendeleev follows the Periodic Law. He uses it as a theoretical hypothesis ${ }^{[2,7,17,18]}$ and does something wonderfully effective. He starts looking for "jumps" in the AW and properties, and thus identifies gaps, which he attributes to "elements yet to be discovered". Figure 9 shows a modern-shaped 1869 Table, which we constructed, with all the then known elements in their respective boxes, while some vacant boxes are either coloured in red or framed in red. These red boxes belong to missing elements and have context of AW and many other properties.

(a)
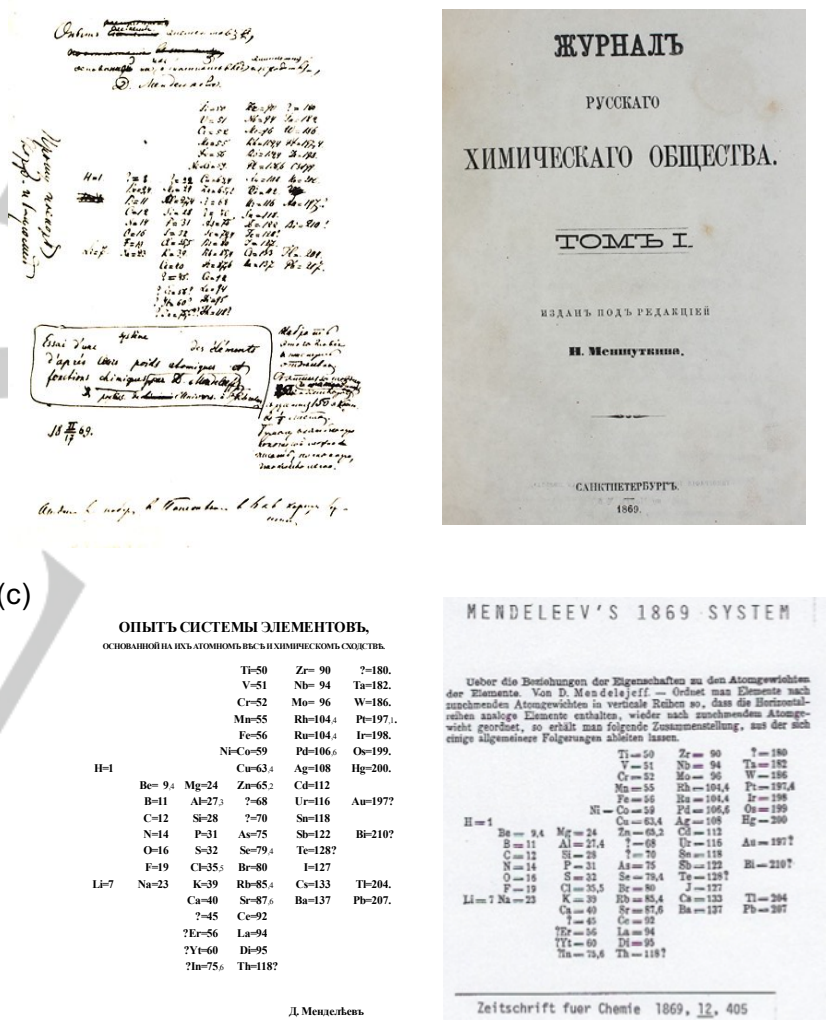

(b)

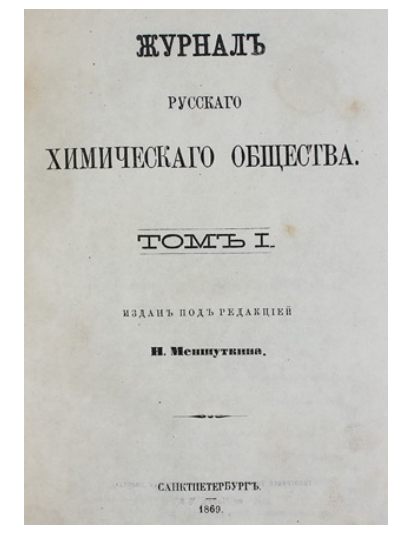

(c)

Figure 8: (a) Mendeleev's hand scribbled Periodic Table dated 18.2.1869. (b) The cover of the $1^{\text {st }}$ Issue of the Journal of the Russian Chemical Society, edited by Nikolai Menschutkin, where the article was published on pp. 66-77. (c) The published 1869 table, and the reprinted one in Zeitschruift fuer Chemie, 1969, 12, 405. [commons.wikimedia.org]

Some of these 'empty' spaces include red printed letters. These are elements, which Mendeleev refers to as eka-elements, where eka is the Sanskrit word for "first one to follow". Thus, below the element $\mathrm{Al}$, there is an empty red box which represents the eka-aluminium (eAl) that is yet to be discovered. There are also eka-silicon (eSi), eka-boron (eB), eka-manganese (eMn), and other missing elements (which follow a known element in second 
and third places). The word eka serves as an exclamation mark for chemists: "something is missing here. Go find it!". Mendeleev had the audacity of not only indicating the "missing" elements, but also predicting their compounds and properties quantitatively and qualitatively [by averaging over neighbours, e.g., $\mathrm{AW}(\mathrm{e}-\mathrm{Al})=68$ ]. As such, Mendeleev creates context in vacant spaces.

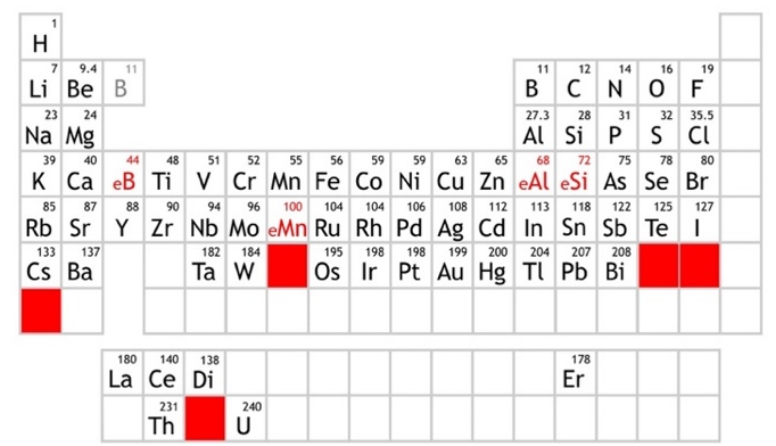

Figure 9: A modern-shaped Mendeleev's Table, with eka-elements printed in red e.g., eAl, and some predictive empty boxes marked in red. Boron $(\mathrm{B})$ is duplicated in grey besides $\mathrm{Be}$; this unusual position intends to show its relationship with eka-boron (eB, which will be discovered and named $\mathrm{Sc}$ ). The e-elements and red boxes indicate "elements yet to be discovered".

Another important feature for a theorist is the is communication with the experimental community. ${ }^{[15]}$ Mendeleev stimulates and challenges the community to go test his bold predictions on the eka-elements. Pushing his proposal further, he also suggests that some atomic weights were erroneous (Te, Os, Ir, Pt, Au and $U$ ) and should be re-determined. Generally, later revision of some of these atomic weights proved him right, though not always (e.g., Te).

The historian Brush, writes: "Having found little evidence for predictivism in many sciences, including physics, I did find it in chemistry, in particular in the case of Mendeleev's Periodic Law". $[7,17]$ By using the word predictivism, Brush means the prediction of something on which there was no clue before; something like prophecy. The philosopher of Science Rom Harré, argues that a successful prediction is rare in science, and he know of one example in chemistry: Mendeleev's. ${ }^{[19]}$ The educator Gorin writes in 1987 "it is absolutely clear that most of the credit must go to Mendeleev". ${ }^{[18 a]}$ In 1996 Gorin added Moseley's name for his seminal work, which caused the replacement of $A W$ by a true atomic constant, the atomic number (AN) as the organizing quantity of the elements. ${ }^{[18 b]}$

\subsection{Predictions and Experimental Discoveries}

Mendeleev's firm belief in the Periodic Law was without bounds, and this made a difference. As he himself expressed this conviction: "Although I have had my doubts about some obscure points, yet I have never once doubted the universality of the [periodic] law". [3b] Indeed, it took only 6 years until an experimental discovery confirmed one of his eka-elements, and after 68 years all of them have eventually been confirmed. Figure 10 , shows eka-aluminium, eka-boron, and eka-silicon on the left-hand column, along with some of the predicted properties, vis-à-vis the discovered Gallium, Scandium and Germanium and their properties. All the predicted properties are in line with experimental findings!

The discovery of Gallium (predicted as eka-aluminium) by Paul Lecoq de Boisbaudran in 1875, was a turning point. Not only did Mendeleev predict the missing element as eka-aluminium, he also insisted that Lecoq made errors, e.g., in the density of the element (4.7 instead of 6.0). Mendeleev immediately fired a letter to LeCoq regarding this mistake. ${ }^{[2,3,7]}$ Some thought this to be arrogant. Nevertheless, when Lecoq repeated his experiments, he reproduced Mendeleev's predictions with remarkable accuracy. Brush $^{[7]}$ defines this prediction as: "one of the most remarkable achievements in science", and adds: "sixty accommodations paled next to the two predictions" (referring also to the eka-silicon discovered in 1880 by Clemens Winkler and named germanium). ${ }^{[17 a]}$

$\begin{array}{lcc} & \begin{array}{c}\text { Predictions } \\ \text { Eka-Aluminum }\end{array} & \begin{array}{c}\text { Discoveries } \\ \text { Gallium }\end{array} \\ \text { AW } & 68 & \text { (discovered in } 1875 \text { by Lecoq) } \\ \text { Density } & 6.0 & 69.9 \\ \text { Atomic Volume } & 11.5 & 5.96 \\ & \text { Eka-Boron } & 11.7 \\ & & \text { Scandium } \\ \text { AW } & 44 & \text { (discovered in } 1879 \text { by Nilson) } \\ & & 43.79 \\ & \text { Eka-Silicon } & \text { Germanium } \\ \text { AW } & 72 & \text { (discovered in } 1886 \text { by Winkler) } \\ \text { Density } & 5.5 & 72.3 \\ \text { Atomic Volume } & 13 & 5.469 \\ \text { Color } & \text { dark gray } & 13.2 \\ \end{array}$

Figure 10: Three eka-elements and their properties as predicted by Mendeleev, shown on the left-hand side, vs. the properties of the discovered elements Gallium, Scandium and Germanium (AW - atomic weight). The names of the discoverers are indicated.

From a philosophical angle, maybe the most remarkable prediction of Mendeleev was the eka-Manganese (marked on his 1871 table - see below). It is known now as Technetium (Tc). ${ }^{[14,}$ ${ }^{20]} \mathrm{Tc}$ is not a naturally occurring element (it is formed as a fission product of Uranium in minute amounts). The element was synthesized in the late 1930s by Emilio Segre (Figure 11) and his collaborators, using nuclear bombardment of Mo by deuterium. ${ }^{[2]}$ Thus, eka-manganese was predicted to have AW $=99-100$, and when it was finally synthesized its AW was determined as 98.9. What a victory for predictivism! It proves the approach of Mendeleev that 'vacant spaces have context'.

\section{The 1871 "Amazing Table"}

While preparing the new edition of his two-volumes of Osnovy Ximii, Mendeleev, changed also his periodic table to the one shown in Figure 12a, which is known as "the amazing table". [18,21,22] Apparently, Mendeleev was exploring the options in his game of Solitaire and changed the format to increase the insight. As can be seen, in comparison to the 1869 table (Figure 8c), in which the chemical families (groups) were arranged horizontally, here in the 1871 Table, the arrangement is vertical as we have it today. In addition, one can see that Mendeleev put the coinage metals $(\mathrm{Cu}, \mathrm{Ag}, \mathrm{Au})$ in both groups I and VIII. This double habitation indicates that using his chemical knowledge, 
Mendeleev is signalling to us that while, by valency the coinage metals belong with the alkali, by chemical behaviour this is not the right place for these nonreactive metals. Another change in 1871 is the correction of the AW for $U$ from 120 to 240 . The amazing table persists with some changes all the way to the 1940 .
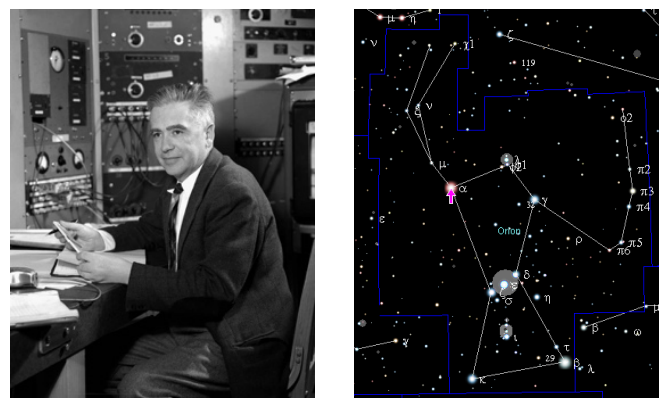

Figure 11: Emilio Segre who participated in synthesizing Tc [previously predicted as eka-manganese) by nuclear bombardment of Mo, and the spectrum of Tc in the giant red star Betelgeuse in the constellation Orion [commons.wikimedia.org]

Mendeleev corresponded continuously with experimental chemists-hunters of new elements. In the 1890s, Ramsay and others ${ }^{[15]}$ discovered new gases, $\mathrm{Ar}$ and $\mathrm{Ne}$, and $\mathrm{Kr}$. Ramsay articulated the Table and organized these gases in place. In his referral to his own discovery he wrote "on the model of our teacher, Mendeleev". ${ }^{[15]}$ Other such gases are being discovered gradually, and in 1905, Mendeleev (who had been reluctant to admit them as new elements ${ }^{[23]}$ ) edits again his book Osnovy Ximii, and generates a new table with Group 0 that includes all the newly discovered gases (Figure 12b). Group 0 means zero valence.

A crucial change was brought about in Mendeleev's Periodic Table, following the discovery by Van der Broek and Moseley, in 1913, of the atomic number (AN) of an element, as the charge of its atomic nucleus. ${ }^{[4,24 a, b]}$ The AN sc pplaced the atomic weight (AW), as e.g., reflected by the borrinciples of Chemistry published in 1918, by Joel Hildebrand (the Associated Professor at the University of Californian, Berkeley). ${ }^{[4,24 c]}$ When the AN was used as the organizing property, some elementreordering, on which Mendeleev insisted, e.g., that Te must appear before I (since the former has valency $=2$ ), were proven to be correct. This underscores Mendeleev's achievement and his intuition, which had led him to create an ordering close to the definit (ne, and to propose changes, that were proven to be correct, III the new ordering set by the atomic number.

The Table is an alive and constantly evolving device; forever young! This is because it is based on a productive principle, the periodic law, which enables predictivism prophesizing about nonexistent elements. As Mendeleev said ${ }^{[8]}$ during his Faraday Lecture (1889): "[the Periodic Law is] like the microscope or the telescope; they should be tools for enlarging our world view".

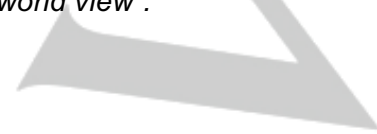

(a)

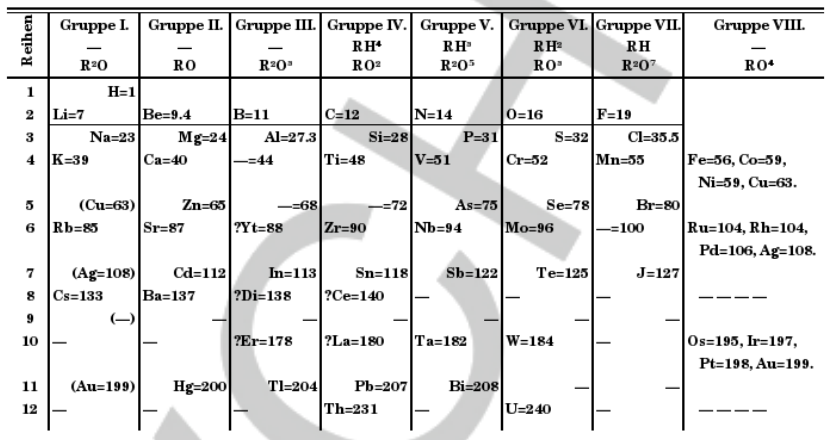

(b)

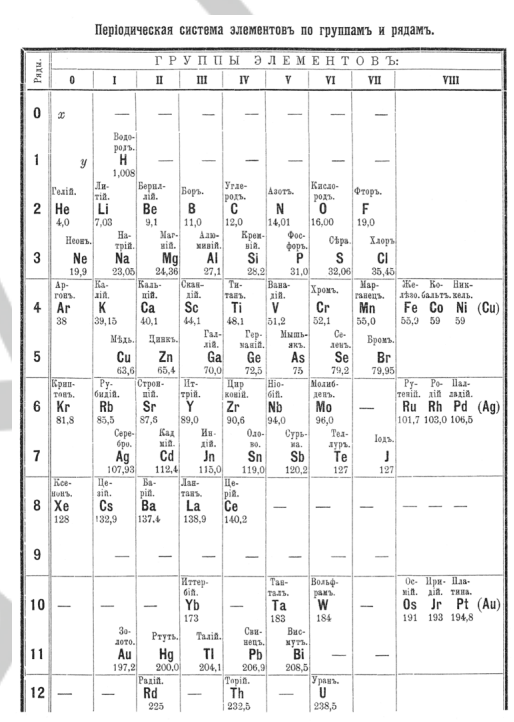

Figure 12: (a) Mendeleev's "amazing table" of 1871 (compare to the 1869 table in Figure 8c). (b) The 1905 Table. [commons.wikimedia.org]

\subsection{Summary of Mendeleev's Intellectual Feat}

In 1882, Mendeleev was awarded the Davy Medal, together with Lothar Meyer. August Michaelis (a professor in the Polytecchnicum in Karlsruhe) declares on the eka-predictions: " $A$ great prediction comparable to the prediction of new planets". ${ }^{[7]}$ By this Michaelis meant, the discovery of Neptune by Galle, after the mathematicians Verrier and Adams explored the strange orbit of Uranus, and concluded that near Uranus there must be an "eka-Uranus". This is how his contemporaries saw his achievement, and this is how we should teach the Periodic table to our students - not as a page with dull facts.

Indeed, Mendeleev is hailed by many. ${ }^{[1 \mathrm{~d}, 9]}$ The historian Bensaude-Vincent, ${ }^{[8]}$ writes that in this book, Osnovy Ximii, and in the Periodic Law, Mendeleev "broke free from his precursors and rivals, by his steady drive towards a general law, without flaws or exceptions"... The periodic law "made a break in the history of chemistry, analogous to the Galilean break in physics ... [and] provided chemistry with a clear distinction of its subject'. The 
plant scientist Stewart, ${ }^{[14]}$ writes "his big three [Ga, Sc, and $\left.\mathrm{Ge}\right]$ had a huge psychological impact". Kedrov wrote on the discovery of $\mathrm{Ga}=$ eka-aluminium: "the scientific world was astounded that Mendeleev, the theorist, had seen the properties of a new element more clearly than the chemist who discovered it". ${ }^{2 a]}$ The historian Brock writes, "The periodic classification of the elements is one of the greatest and most valuable generalizations in science... It was able to adopt to the deeper analysis of structure of matter revealed by nuclear physics..., the Eightfold Way of Murray Gell Mann owes much to Mendeleev .... [and his] philosophical mind that elevated him above ... the empirical enquiries of his contemporaries". ${ }^{[2 a]}$ Strathern writes: "Mendeleev has classified the building blocks of the universe". ${ }^{[3]}$ Finally, the philosopher Scerri summarizes that Mendeleev: "elevated the ordering of the elements by atomic weight to the status of a law. ${ }^{[1 d]}$

In 1955 element 101 was discovered and duly took its place in the Periodic Table, and was named mendelevium (Md), in recognition of Mendeleev's supreme achievement. Appropriately, Md was proven unstable liable to spontaneous nuclear fission, slightly reminiscent of the eruptive and excitable character of the man after which it was named. In 2014 Mendeleev's 1869 paper, which included the Table, was cited for "Chemical Breakthrough Award" by the Division of the History of Chemistry of the American Chemical Society. ${ }^{[25]}$

\section{The Periodic Table in Literature, Music and Arts}

The Periodic table has become a universal icon, which has been incorporated into literature, music and arts. We are going to say something about a literature piece, which salutes the Table: The Periodic Table by Primo Levi, ${ }^{[26]}$ a chemist who worked in Auschwitz. We then shift to another scientist and writer, Oliver Sacks, whose life was intertwined with the love of chemistry, as he recounts in his book "Uncle Tungsten". ${ }^{[27]}$ A brief mention will also be made of some literary works that deal with the discovery of new elements. Subsequently, we'll flash quickly a few music albums, which include the Table and the elements, and some artworks that refer the elements/chemistry.

\subsection{Chemistry, Literature, and Primo Levi}

Figure 13 shows a tip of an iceberg of chemistry's mentions and incorporation into literature. Nevertheless, the book that surpasses all others, from the point of view of chemistry, is "The Periodic Table" by Primo Levi in Figure 14.

"The Periodic Table"[26] was chosen by the Royal Institution as the best science book ever written. Nevertheless, it contains fiction and great literature. It offers unique insight into Primo Levi's innermost thoughts, the experience of Italian Jews in Turbulent times, and his own experience in Auschwitz. Primo Levi uses 21 elements as codes or metaphors of human situations and characters, showing the entanglement of matter and spirit. The book is poetic and its reading is a beguiling experience. We shall limit ourselves here to the overflow of feelings expressed by Levi about the discovery of the Periodic Table and his own poetic love of chemistry as manifested in the closing chapter "Carbon".

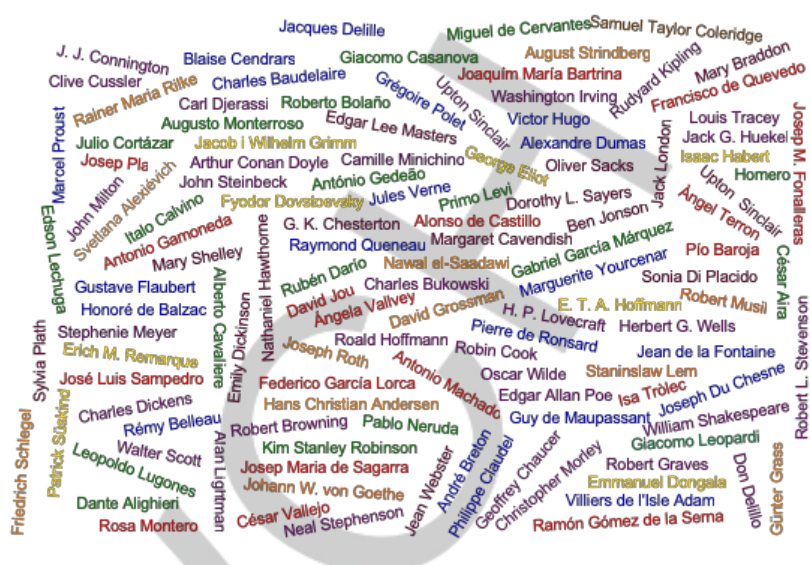

Figure 13: A collage (created by S. Alvarez) of names of writers who mention chemistry, its elements, and the Periodic Table in their books.

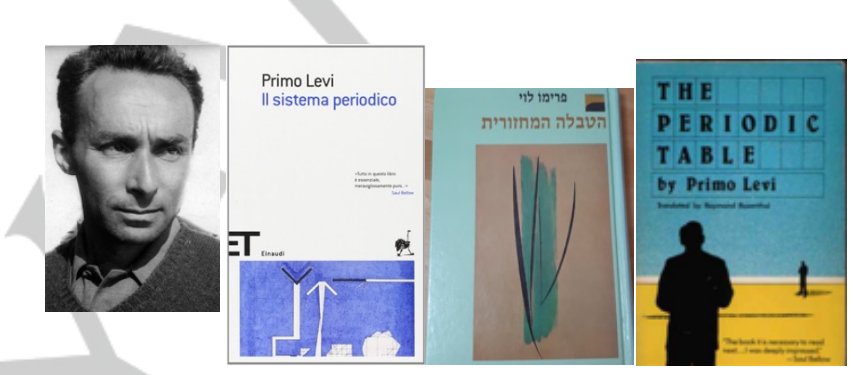

Figure 14: Primo Levi, and his book (Ref. 26) in Italian (original language), Hebrew and English translations

\subsection{The Story of Iron}

This story "Iron" includes lofty poetry on the Periodic Table and the science of Chemistry. The chapter starts with Levi's $2^{\text {nd }}$ year course, Qualitative Analysis (which most chemists still take during the early stages of their education). He tells us that the "ascetic and distracted professor D." hands him and his lab-mate (Sandro), a sample of powder for analysis. The practical Sandro identifies iron in the powder, while the poetically inclined, Primo Levi identifies the character: Sandro is made of iron (page 40 in the English translation)...

Levi continues to tell us about Sandro and himself: "Sandro chose chemistry as a trade that dealt with tangible things; a way to earn one's bread". On the other hand, Primo Levi came to chemistry because in his view: "the nobility of man acquired in hundred centuries ... lay in making himself the conqueror of matter... Conquering matter means understanding it'. Therefore, says Levi, "Mendeleev's Periodic Table, [which he and Sandro were studying at this stage], was poetry, loftier and more solemn than all the poetry we [Sandro and he] had swallowed in the liceo [high school]".

And Levi adds: "come to think of it, it even rhymed! ... Such that if one looked for the bridge, the missing link between the world of words and the world of things... it was there in our smoked-filled labs and our future trade".

Sandro's grade jumped from $C$ to A. Later he would join the resistance, gets caught, and end up being executed by the Fascists - the 'iron-friend' is murdered by evil. 


\subsection{Levi's Dialog with the Physicist Tullio Regge (1981)}

In 1984 Tullio Regge interviewed Primo Levi, and they had a fascinating dialogue. ${ }^{[29]}$ Here is part of this dialogue:

Tullio: "I like where you say that the periodic table is poetry. But, what's with the rhyme?"

Levi: "The expression may seem paradoxical, but the specification of rhyme is right. In the graphic form of the table of the periodic system, each line ends with the same syllable, which is always composed of a halogen plus a rare gas: fluorine + neon, chlorine plus argon, and so on... But in the same sentence there is evidently more. There is an echo of the great discovery, one that takes your breath away; an emotion (even aesthetic, even poetic) that Mendeleev must have felt when he intuited that by ordering the elements [as he did], chaos gave rise to order..."

And Primo Levi continues to tell Tullio: "And Mendeleev subsequently finds empty boxes that had to be filled, since 'all the predicted properties can exist there'. This is a prophetic work: foreseeing the existence of unknown elements, which were all subsequently discovered in time, predict or create symmetry, put something in the right place, it is a common mental adventure of the poet and the scientist".

\subsection{The Story of Gold and the Chapter on Carbon}

In the chapter "Gold" Primo Levi tells us about one of the most beguiling stories in his book. And so he writes: "In the fall of 1942 there were seven of us friends from Turin ... living in Milan, having arrived for different reasons in the large city which the war had rendered inhospitable. After Guilia's marriage, I had remained alone with my rabbits. I felt a widower and an orphan and fantasized about writing the saga of an atom of carbon, to make people understand the solemn poetry, known only to chemists, of chlorophyll photosynthesis: and in fact, I did eventually write it, but many years later, and it is the story with which this book concludes".

The entire story in the chapter on carbon is a long and wonderful fictional-prose, in which Primo Levi's love of chemistry unfolds. It should be made a compulsory reading for chemists, and for anyone who is moved by the achievements of the human genius.

\subsection{Oliver Sacks in Uncle Tungsten}

Like Primo Levi, Oliver Sacks (London, 1933- New York, 2015) wrote his memoirs which intertwine life's events and chemistry, ${ }^{[27]}$ and which stretch all the way from his childhood in Britain during World War 2 to his life in the US as a distinguished neurologist. In the ending Afterword chapter, he mentions his friendship with Roald Hoffmann and how this might have been the trigger for his decision to write the book, which he entitled Uncle Tungsten, after his uncle Dave who introduced him to the wonders of metals. The secondary title of the book, Memories of a Chemical Boyhood, tells us about the flavor of the book; it combines personal memoir with his love for chemistry and a short history of Chemistry. Sacks describes in a masterly way his precocious experiences with metals, more or less spectacular reactions, colours and spectra, scents and stenches and, overall, the periodic table to which he devotes a chapter titled "Mendeleev's Garden". And so he writes in the chapter:

\begin{abstract}
"The periodic table was incredibly beautiful, the most beautiful thing I had ever seen. I could never adequately analyze what I meant here by beauty simplicity? coherence? rhythm? inevitability? Or perhaps it was the symmetry, the comprehensiveness of every element firmly locked into its place, with no taps, no exceptions, everything implying everything else."
\end{abstract}

Another chapter that should be compulsory reading for youngsters is the one dealing with odours and explosions. Here everything is connected: chemical reactions (even the most violent ones), colours, gems, laboratory accidents, the history of chemistry, the smells of fruits or hospitals and of war gases. All in just thirteen brilliant pages! For his 80th birthday he published an article in The New York Times that started like this: "Last night I dreamed about mercury - huge, shining globules of quicksilver rising and falling. Mercury is element number 80 , and my dream is a reminder that on Tuesday, I will be 80 myself."

\subsection{Discovery of New Elements in Fiction}

The Periodic Table and specifically, the discovery and prediction of new elements is a topic that has inspired several writers. Let us give here just a small sample.

Herbert George Wells, in his science-fiction novel The War of Worlds (1898) identifies an unknown element through its emission spectrum. Upton Sinclair, describes in his book $A$ Comedy of the Year 2000 (1907), the concerns raised by the discovery of a new highly-radioactive element, "radiumite". Howard P. Lovecraft in the tale The Dreams in the Witch House (1932) conveys the anguish produced by the discovery of an element that does not fit into the Periodic Table. The French writer Raymond Queneau, in his novel Les enfants du Limon (1938) predicts the discovery of a new element, "danoémium", that should have an atomic weight close to 250 . Surprisingly, the first isotope of californium, ${ }^{245} \mathrm{Cf}$ was obtained in $1950 .{ }^{[29]}$ Cartoonist Hergé, in The Shooting Star (1942) that forms part of the series The Adventures of Tintin describes the excitement of Professor Decimus Phostle as he analyzes an emission spectrum and realizes that he has discovered a new element, that should be named "phostlite" in his honor.

\section{Music, Art, Chemistry and the Periodic Table}

Let's devote a few words on how chemistry is represented in music albums and in visual/conceptual arts. Essays on these two topics were written before by one of us (SA), ${ }^{[28,31,32]}$ and another one is due on time by EC. The reader will note that these works 
are not always related to chemistry in a deep and a well elaborated connection, and in some cases this connection may appear superficial. Nevertheless, these musical and art works reflect the trickling of the Periodic Table, the elements and chemistry as such, into other fields of human culture.

\subsection{Music Albums}

Jerry Fielding (born as Joshua Feldman) was a musician most known for the music he composed for famous movies, e.g., The Wild Bunch and Straw Dogs, both directed by Sam Peckinpah and nominated for the Oscar awards. In 1958 he recorded the 'Fielding Formula', a Jazz album in which Fielding likens chemistry to music. As can be seen in Figure 15, the chemicals are poured, and en-route down they become musical notes, and when they mix at the flat bottom flask these notes create chemicals. The magic of Chemistry...

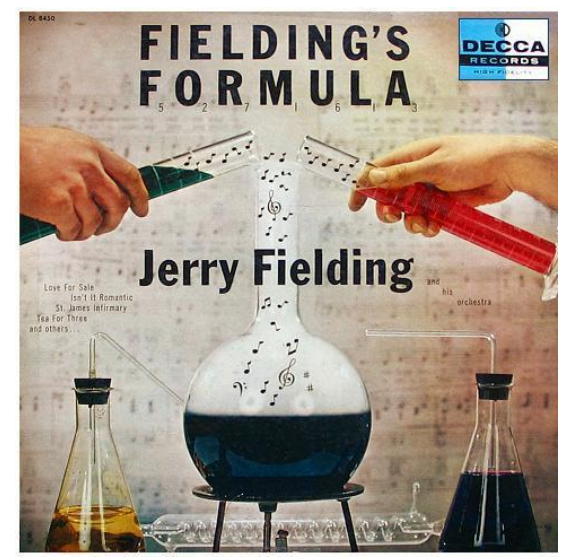

Figure 15: The Album Cover for "Fielding's Formula" (Decca Records, 1958)

King Crimson is an English band and one of the most important bands of progressive rock genre, known also as classical or symphonic rock and represented among others by Jethro Tull and Pink Floyd. In 2014 King Crimson released the first of a series of tour albums named "The Elements". The front and back covers of The Elements - 2016 Tour Box are shown in Figure 16 , where the name of the band is represented by the elements $\mathrm{K}$ and $\mathrm{Cr}$. The names of the band members are represented, in turn, by other elements: $\mathrm{K}$ (Jakko Jakszyk), Rn (Robert Fripp), Lv (Tony Levin), Cs (Mel Collins), H (Gavin Harrison), Sc (Jeremy Stacey), Mo (Pat Mastelotto) and Rf (Bill Rieflin). This imagery has been used in posters, T-shirts and other merchandise during the tour.

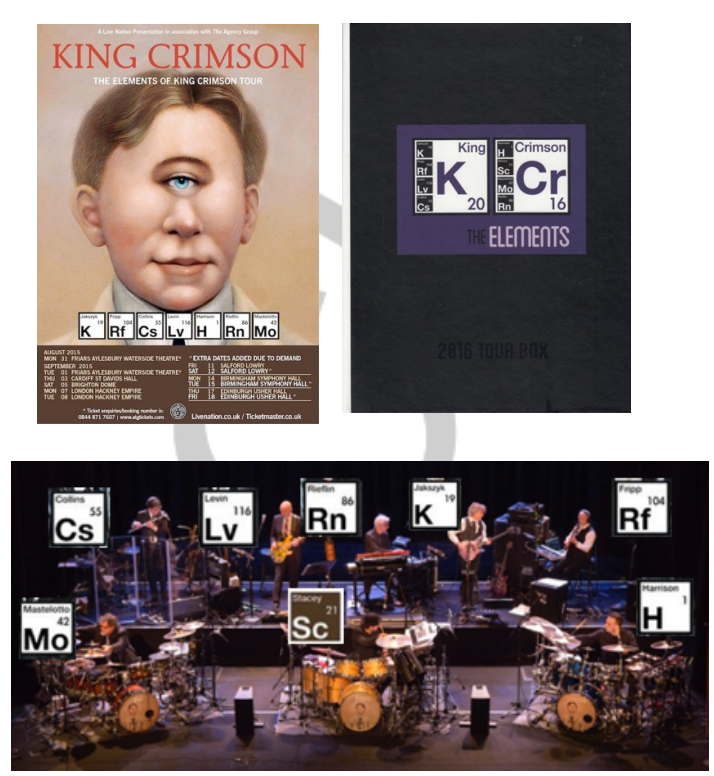

Figure 16: In the upper left is the King Crimson's advertisement for 'The Elements of King Crimson Tour' in 2015. The upper right item is The Elements of King Crimson - 2016 Tour Box, Discipline Global Mobile, 2016. At the bottom image, are the members of the band playing live together with their element symbols.

And here in Figure 17, are the covers of John Mayer's album, "Room for Squares", which was released in 2001, and is his most highly selling album to date. The title is a take on the title of the Soul Jazzist, Hank Mobley, who released an album called "No Room for Squares" (referring to the discrimination of blacks in the US). The covers in Figure 17, show the Periodic Table in its modern shape.

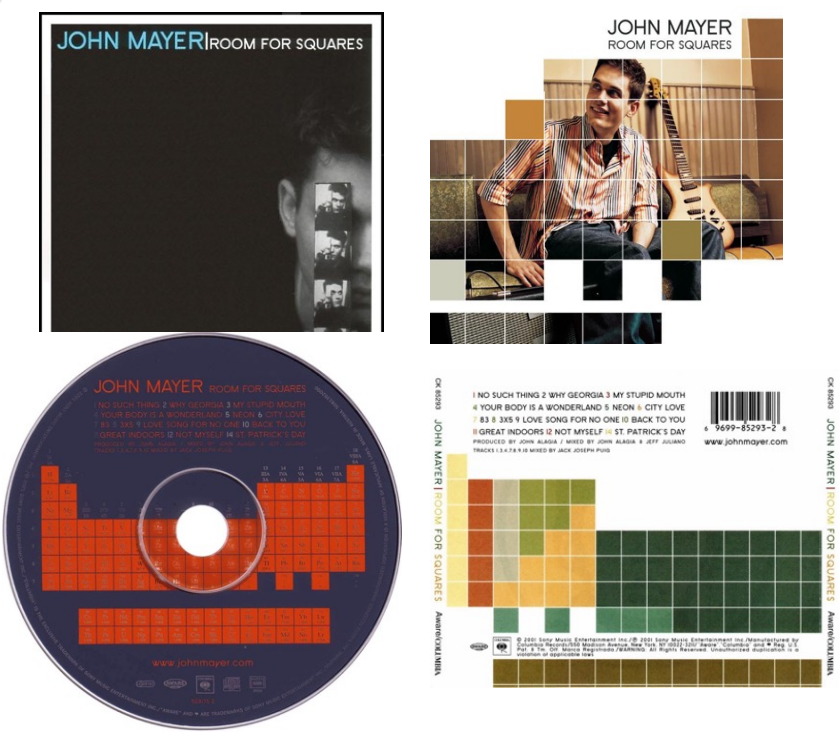

Figure 17: John Mayer's album Room for Squares: (Aware Records, 2001 (upper left item)), Columbia Records, 2001(other items). 
Milo Aukerman, a biochemist and the lead singer of the 'Descendents', designed the idea behind the album 'Hypercaffium Spazzinate', in which the band represented by a cartoon tries to synthesize a molecule (Hypercaffium Spazzinate) with better properties than caffeine (Figure 18 left). The back cover of the album (Figure 18 right) represents the songs as elements of a mini-periodic table.
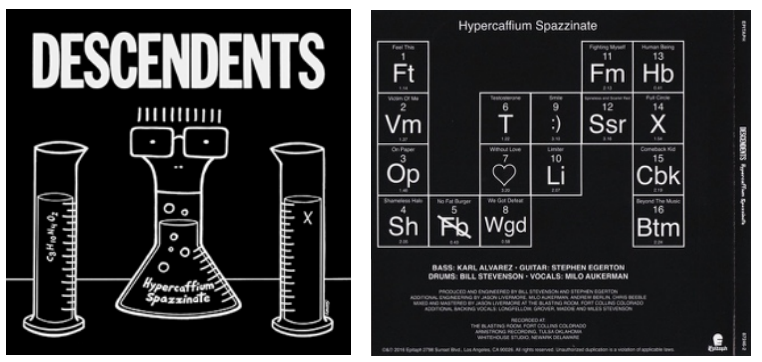

Figure 18: The album 'Hypercaffium Spazzinate' by the 'Descendents'. On the left is a cartoon representation of the band trying to synthesize caffeine. The back cover on the right, shows a mini-periodic table of the songs in this album. (Descendents. Hypercaffium Spazzinate, Epitaph, 2016; G. Hunt, R. Mukhopadhyay, Punk rock band Descendents showcase science on latest
album
cover,
Asbmbtoday.

http://www.asbmb.org/asbmbtoday/201606/Descendents/)

In the album Everything/Everything by Simon Bookish (Figure 19), the cover portrays the musician playing with or selecting elements of the Periodic Table.

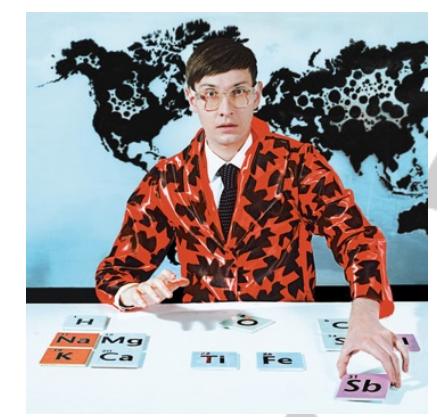

Figure 19: Simon Bookish. Everything/Everything (Tomlab, 2008).

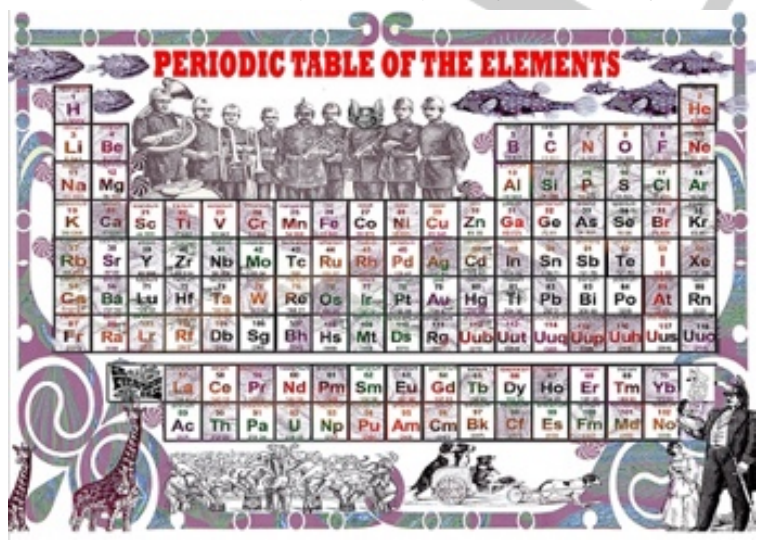

Figure 20: A Periodic Table included in the limited gold vinyl copies of the 'Chemistry Set' band. (The Endless More and More, Regal Crabomophone, 2016)
Finally, the limited gold vinyl copies of the album the Endless More and More by the British band 'The Chemistry Set' included a psychedelic Periodic Table (Figure 20).

An enchanting song is The Elements, which was written by Tom Lehrer (Figure 21), and is included in his album "An Evening Wasted with Tom Lehrer". The lyrics of the song are a recitation of all the 102 elements (known at the time), sung to the tune of Arthur Sullivan's "Major General's Song" from the Pirates of Penzance. Lehrer recites all the elements in a frantic pace, which he breaks once or twice with a long sigh... and then he utters, "these are the only ones of which the news have come to Harvard, and there may be many others but they haven't been discovered...". This is a vivacious and amusing song, which one of us (SS), and the late Joel Bernstein to whom this essay is dedicated, used to play in their class of General Chemistry. The MP4 of this song is available in the internet.

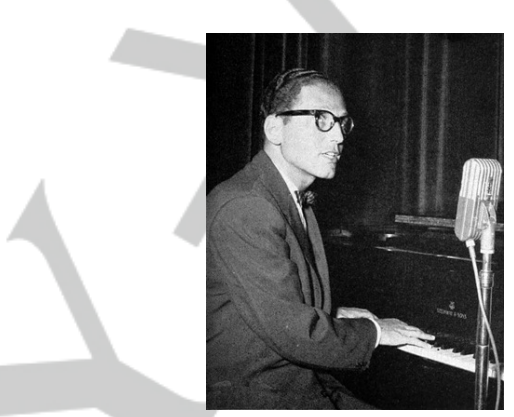

Figure 21: Tom Lehrer, singing and playing the song "The Elements" in UCLA (1960). The song can be found as an MP4 on the internet, or in the album, "An Evening Wasted with Tom Lehrer". [commons.wikimedia.org]

More recently, the Canadian youtubers Mitchell Moffit and Gregory Brown have released through their AsapScience channel a song that mentions 118 elements to the tune of Jacques Offenbach's Infernal Galop from the operetta Orpheus in the Underworld. And a song that every chemist should know is "The Demi Song", interpreted by one of the fathers of folk music, Pete Seeger.

Andrew Stiller (Washington, DC, 1946) composed in 1988 A Periodic Table of the Elements, translating into music the properties of the elements in descending order of atomic number. It can be found in the compact disc $A$ descent into the Mae/strom interpreted by the Orchestra 2001(MMC Recordings, 1995).

A related work, Chemical Elements 2018: a Music Mosaic, has been composed by Ernest Giralt-Lledó, emeritus professor of Organic Chemistry at the University of Barcelona. In it he combines 118 musical fragments that reflect the character of the different elements as well as their periodicity, showcasing a variety of instrumental combinations and musical styles. The Norwegian composer and saxophone player Ole Mathisen released his fine disc Periodic Table in 2010 (Jazzheads, 2010), which contains pieces dedicated to ten different elements. ${ }^{[31]}$

In a recent lecture tour in India, one of us (SS) gave the Platinum Jubilee Lecture on the Periodic Table, in the CSIR-IICT Institute in Hyderabad. As a prelude to the lecture a choir of young women from the "St Francis Degree College For Women" sang "The Elements", for which they composed the music and performed, after listening to the Tom Lehrer's MP4. The Periodic 
Table is certainly spreading beyond its little chemical universe to become a universal cult.

\subsection{Artwork}

In 1968, the artist and chemist George Brecht (Figure 22) produced a series of works entitled The Chemistry of Music. In the series he also paid homage to his father who was a flutist. In all these works, music notes become material and vice versa (one of many examples is Figure 23). A very profound idea that equates the creative combination of notes that forms music to the combination of elements/molecules that forms complex compounds.

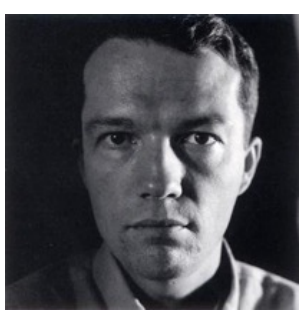

Figure 22: The portrait of George Brecht (photo George Maciunas, 1964 MoMA). To the best of our judgement, this portrait is free to use in articles as the present one [https://en.wikipedia.org/wiki/File:GeorgeBrecht.jpg]

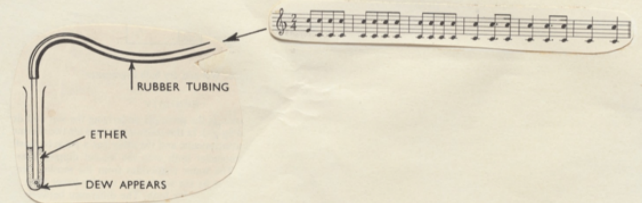

Figure 23: A typical example of an artwork by George Brecht on the interconversion of music notes and materials, here showing ies of musical notes pouring into a test tube and materializing as dew. [1 $\mathrm{g}$ permission: when becomes available they will tell us how to cite the work.]

The artist Miquel Barceló (Felanitx, Mallorca, 1957), in addition to his boundless creativity and very personal style, is concerned about the elements used in his paintings. In his Notebooks of Africa ${ }^{[33]}$ he writes: At the back of the dark shed where my materials hibernate, only the bags with mineral pigments have held up. All the 1 or 5 kilo bags are covered by a reddish ochre colour. Once everything was dusted, I found blazing colours: chromium yellow, cobalt blue, cadmium red, titanium white. A similar care for the nature of the pigments used for his works is reflected in the letters of Vincent Van Gogh to his brother Théo. In classical treatises on painting, such as Cennino Cennini's /I libro dell'arte, we can see the variety of elements present in pigments: gold, silver, copper, iron, carbon, sulfur and arsenic (combined in orpiment and in realgar), lead, titanium, tin, calcium, barium, chromium, cadmium, mercury and selenium. ${ }^{[28]}$

Probably the element most recently incorporated to the artists' palette is yttrium. It has the formula $\mathrm{Y}_{0.8} \mathrm{Mnn}_{0.2} \mathrm{O}_{3}$ and is known as YInMn blue. It was first prepared in 2009 by Mas Subramanian at the Oregon State University while attempting to obtain materials for electronics applications by making solid solutions of the oxides $\mathrm{YlnO}_{3}$ and $\mathrm{YMnO}_{3}$. This pigment is held in the Forbes pigment collection of the Harvard Arts Museums, together with many others that go back to the middle ages and constitute a visual history of color. ${ }^{[34]}$

As a sequel of her audiovisual work, Frequencies, the multimedia artist Eugènia Balcells, active in New York and Barcelona, developed in 2011 a unique periodic table, which she entitled Homage to the Elements. In this piece, each chemical element is represented by the collection of lines of their emission spectra, as coloured barcodes of the elements (http://eugeniabalcellsfoundation.org/homage-to-the-elements). Therefore, energy and matter that form our visual universe are represented in a unique metaphor of the chemical universe. As such, Eugènia Balcells fuses together two of the most remarkable icons of the advances in Science at the end of the 19th century, the emission spectra that were so useful for the discovery of new elements, and the Periodic Table that encapsulates our chemical knowledge.

Blair Bradshaw, a San Francisco-based painter is inspired by the Periodic Table as a graphic element and as a way of organizing complex information systems. His colored versions of the periodic table and of fragments of it are stunning. Moreover, he transports stylistic aspects of the Periodic Table to many other of his artworks, including boats, Metro signs or the North American flag. This captivating work can be gleaned from his website: http://blairbradshawstudio.com .

\section{Chemistry is Everything and Everything is Chemistry}

It is time to end this essay that celebrates the 150 years of the Periodic Table with what we probably all know: Mankind is made of chemical matter, the same matter as any other matter in our universe. We are creatures made of 118 LEGO pieces that are called elements, and are collected in the Periodic Table. What remains after each one of us dies are our atoms/elements that are

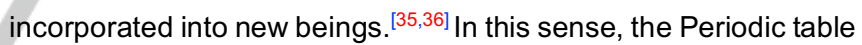
is a compact "book of census" of our globe.

This metamorphosis is expressed beautifully by Bruno Schultz, the writer, who perished in a concentration camp: ${ }^{[37]}$

"Matter is prone to endless richness, an inexhaustible vital force, and a beguiling power of temptation that enriches us to become creators on our own right... All matter flows out from endless possibilities... Anyone may knead and shape it; it submits to all. All arrangements of matter are impermanent and loose, liable to retardation" [Bruno Schultz, The Next Book of Genesis]

The Bible condenses it Periodic Table into a single unique phrase with six elements: "only the gold, silver, (copper), iron, tin and lead..." (Book of Numbers 31:22). Tuuay we know of 118 elements. But, indeed, as Bruno Schultz wisely tells us, matter is endless. Several years ago, Pekka Pyykkö computed the electronic configurations of atoms up to atomic number 172 , which will presumably all enjoy some stability (which is defined by IUPAC as a lifetime of $10^{-14} \mathrm{sec}$ ). ${ }^{[38]}$ Cabalists 
say that the real number is 273 . Atoms form the building blocks of our universe, hence Chemistry and its Periodic Table are immortal and endless sources of knowledge that promise much work ahead for many, many chemists, engaged in creative manipulation of matter

\section{Epilogue}

We are embedded in the magic of chemistry. Mendeleev, while not alone,$^{[1 \mathrm{~d}, 18]}$ deciphered this Rosetta Stone, created the Table, and thereby touched the secrets of being. Element 101 (Md) is named after him.

Primo Levi uncovered the poetry and creativity encapsulated in the Table and the Gordian link between Spirit and [Chemical] Matter. His service to the world of chemistry is enormous! As chemists, we should all read Levi's book, make it part of the teaching curriculum, and strive to name a new elements after him. Le (119) is one possibility to consider...

\section{Acknowledgements}

SS is supported by the Israel Science Foundation (Grant ISF 520/18). SA is supported by MINECO CTQ2015-64579-C3-1-P the Spanish Structures of Excellence María de Maeztu program through grant MDM-2017-0767, and AGAUR (Generalitat de Catalunya) through grant 2017-SGR-1289.

Keywords: Periodic Table $\cdot$ History of Chemistry $•$ Mendeleev Primo Levi • Oliver Sacks

[1] This is not a historical account but an essay. We therefore avoided any discussion on who (in the line of contributors to the idea of periodicity) deserves more credit. In the end, the primacy went to Mendeleev because of his intense polylogue with the experimental community. This essay also avoids any detailed discussion of the development of the idea of periodicity. For recent essays, with some historical details, before and past Mendeleev, and discussions of "errors", and of the explanation of the Periodic Law through Quantum Mechanics, as well as on experimental derivation of the overarching periodic property of the element, the "electroaffinity" (todays' "electronegativity"), see: (a) A. A. Endriko and H.-J. Lunk, ChemTexts, 2018, 4 (1-13); (b) B. Hargittai, I. Hargittai, Structural Chemistry, 2019, 30, 1-7. (c) For discussion of the Periodic Tables of Newlands vs. Mendeleev, see: M. D. Gordin, AMBIX, 2018, 65, 30-51. (d) For a thorough study of the development of the Periodic Table, see: E. M. Scerri, The Periodic Table - Its History and Its Significance, Oxford University Press, 2007 (specifically on Mendeleev, see pp. 101-157). (e) For a detailed "history" of the development of Mendeleev's thinking and his Periodic Table, see: I. S. Dimitriev, Historical Studies in the Physical and Biological Sciences, 2004, 34, 233-275. (f) On how did quantum mechanics explained the Periodic Table, see: B. Friedrich, Found. Chem. 2004 6, 117-132. (g) Clara Haber worked with Richard Abegg and contributed to experimental quantitation of electroaffinity. See: B. Friedrich, D. Hoffmann Clara Haber Née Immerwahr: in and Out of Her Element, in: Women in their Element. B. van Tiggelen \& A. Lykknes (eds.), World Scientific, Singapore, 2019. (h) More details can be found in the monographs by Brock, Gordin, Strathern, etc. cited below.

[2] W. H. Brock The Norton History of Chemistry, W.W. Norton and Co. New York, 1993; (a) On Mendeleev, Chapter 9, pp. 311-354. (b) On The four Elements and Alchemy, Chapter 1, pp. 1-40.

[3] P. Strathern, Mendeleyev's Dream: The Quest for the Elements", Hamish Hamilton, London, 2000: (a) pp 1-7. (b) The Chapters Mendeleyev and The Periodic Table, pp. 262-294. (c) the chapter on the four elements and the Greeks, the Alchemists, pp 9-69.
[4] The plot of the number of elements discovered per year is a new updated version of that published by S. Alvarez, J. Sales, M. Seco. "On books and Chemical Elements". Found. Chem., 10, 79-100 (2008).

[5] R. Siegfried, From Elements to Atoms: A History of Chemical Composition. American Physical Society, Philadelphia, 2002. (a) pp. 163-212 - Lavoisier and his contemporaries. (b) pp. 127-138 on the return of the four elements in the $18^{\text {th }}$ Century. (c) pp. 234-264 on Dalton and the chemical atomic theory.

[6] a) $\mathrm{H}$. Aldersey-William, Periodic Tales: A Cultural History of the Elements from Arsenic to Zinc, Penguin Books Ltd. London, 2011; b) B. Bryson, A Short History of Nearly Everything, Broadway Books, NY, 2004, pp. 168-170; 299304

[7 ] S. G. Brush, Isis, 1996, 87, 595-628.

[8] An assessment and definition of Mendeleev's achievements, see: B. Bensaude-Vincent, BJHS, 1986, 19, 3-17.

[9] For the passage from Mendeleev's chemistry to atomic physics and nuclear physics, see; M.E. Kibler, Foundations of Chemistry, 2007, 9, 221-234.

[10] Dmitry Mendeleev| Ten Facts on the Father of the Periodic Table: https://learnodo-newtonic.com/dmitri-mendeleev-facts

[11] See: (a) https:en.Wikipedia.org//wiki/Dmitri Mendelee; https://www.khanacademy.org/partner-content/big-history-project/stars-andelements/knowing-stars-elements/a/dmitri-mendeleev

[12] G. Woods, Mendeleev - the man and his legacy... 2007, https://eic.rsc.org/feature/mendeleev-the-man-and-his-legacy-

/2020190.article

[13] D. Q. Posin, Mendeleeyev, the Story of a Great Scientist, Mc Graw-Hill, New York, 1948

[14] P. J. Stewart, Mendeleev's predictions: success and failure. Foundations of Chemistry, 2018, https://doi.org/10.1007/s10698-018-9312-0

[15] Yu. I. Solv'ev, J. Chem. Ed. 1984, 12, 1069-1071.

[16] B. N. Menschutkin, Nature, 1934, 133, 946

[17] a) S. G. Brush, Hist. \& Philos. of Science Assoc. 1994, 2, 133-145; b) On "predictivism": S. G. Brush, Stud. Hist. Phil. Sci. 2007, 38, 256-259.

[18] a) G. Gorin, Mendeleev, Meyer and the Periodic Table. Presented at the Spring 1987 National Meeting of the American Chemical Society, Denver Co. HIST-010; b) G. Gorin, J. Chem. Ed. 1996, 73, 490-493.

[19] R. Harré, The Principles of Scientific Thinking, Chicago Press, , 1970., p.

[20] On Tc: R. H. Garstang, S. Little, and I. Little, Mercury, 1983, 152-155

[21] M. Laing, The periodic tables of Mendeleev, https://eic.rsc.org/feature/theperiodic-tables-of-mrdeleev/202025;

[22] M. Laing, J. Chem. Ed. 2008, 85, 63-67.

[23] M. D. Gordin, A Well Ordered Thing. Dmitri Mendeleev and the Shadow of the Periodic Table, Basic Books, Ne Tr k, 2004

[24] a) A. Van der Broek, Nature, 19 2, 372-373; b) H. G. J. Moseley, Phil. Mag. 1913, 26, 1024. For deflection of $\alpha$ particles from the nucleus, see: $E$. Rutherford, Nature, 1913, 92, 423; c) J. H. Hildebrand, Principles of Chemistry. The Macmillan Co. New York, 1918.

[25] D. E. Lewis, Bull. Hist. Chem. 2014, 39, 1-5.

[26] P. Levi, The Periodic Table, 1975 (in Italian by Einaudi, Torino), 1984 (in English translation, Schocken Books), 1987 (in Hebrew translation, Keter Ltd.)

[27] O. Sacks, Uncle Tungsten: Memories of a Chemical Boyhood, Vintage Book, NY, 2002

[28] S. Alvarez, Dones, homes i molècules, Edicions Universitat de Barcelona, Barcelona, 2017

[29] Primo Levi, Tullio Regge, Dialogo, Einaudi, Torino, 2005 (1st ed. 1984).

[30] S. G. Thompson, K. Street, Jr., Al Ghiorso, G. T. Seaborg, Phys. Rev. 1950, 78, 298.

[31] S. Alvarez, New J. Chem. 2008, 32, 571-580.

[32] S. Alvarez. "Tres artistas y su material de laboratorio: George Brecht, Víctor Grippo y Hermann Nitsch", An. Quím., 114, 19-24 (2018).

[33] M. Barceló, Carnets d'Afrique, Gallimard, Paris, 2003.

[34] K. Trinder, V. Finlay, An Atlas of Rare and Familiar Colour. The Harvard Art Museums' Forbes Pigment Collection, Atelier Éditions, Montreal, 2017.

[35] a) S. Shaik, Angew. Chem. Int. Ed. 2003, 42, 3208-3215; b) S. Shaik, Chemistry as a Game of Construction: The Bond Click Way. Wiley-Interscience, Hobboken, New Jersey, 2015, Chapter 1, p. 30.

[36] F. Tibika, Molecular Consciousness. Inner Tradition, Bear \& Co., Rochester, NY, 2013, p. 17.

[37] Bruno Schulz, Treatise on Mannequins, or the Next Book of Genesis, Kompánia (Hungary), p. 31 in the Hebrew translation.

[38] P. Pyykkö, Phys. Chem. Chem. Phys. 2011, 13, 161-168. 
Entry for the Table of Contents (Please choose one layout)

Layout 1:

\section{ESSAY}

A story recounting Mendeleev's life, his founding of the Periodic Table, its impact on chemistry, and its universality through literature, with special attention to Primo Levi, pop and classical music and plastic arts

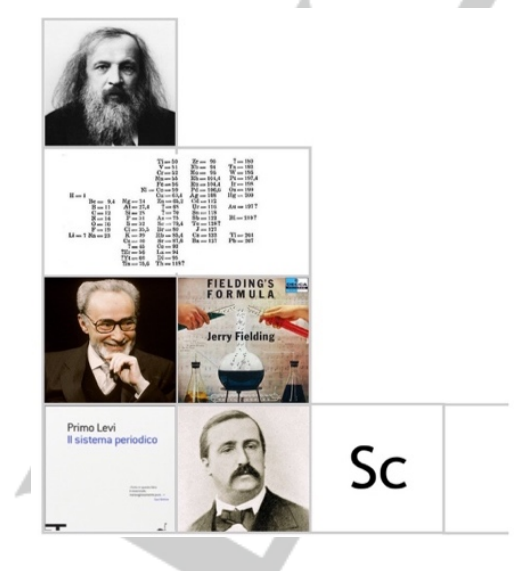

Sason Shaik*, Eduard Cremades* and Santiago Alvarez*

Page No. - Page No.

The Periodic-Table - A Universal Icon: Its Birth 150 Years Ago, and Its Popularization Through Literature Art and Music 